\title{
A Case Report of Cervical Thymic Cyst and Review of Literature
}

\author{
Madhira Srivalli • Hamid Abdul Qaiyum • \\ Prayaga N. Srinivas Moorthy $\cdot$ Kolloju Srikanth
}

Received: 13 September 2009/Accepted: 17 September 2009/Published online: 27 January 2011

(C) Association of Otolaryngologists of India 2011

\begin{abstract}
We are reporting a case of 10-year-old female child with an asymptomatic left sided cystic neck mass who underwent surgical excision. She was diagnosed as having a cervical thymic cyst based on histopathologic findings. The review of available literature on thymic cyst has shown that cervical thymic cyst is a rare occurrence, but should always be thought of in the differential diagnosis of cystic masses in the neck especially presenting in children.
\end{abstract}

Keywords Thymic cyst - Pediatric neck masses $\cdot$ Ectopic thymus

\section{Introduction}

The thymic cyst is a rare possibility in differential diagnosis of neck masses in children and the diagnosis most often is postoperative based on pathological examination of the resected specimen. The thymic cysts in children are more often mediastinal but may be found at any level along the normal descent of thymus from the angle of the mandible to the superior mediastinum $[1,2]$.

\section{Case Report}

A 10-year-old girl presented to our out-patient department with a swelling on the left side of neck of 4 years duration

M. Srivalli ( $₫) \cdot$ H. A. Qaiyum · P. N. Srinivas Moorthy ·

K. Srikanth

Department of E.N.T.-Head \& Neck Surgery, Princess Esra

Hospital, Deccan College of Medical Sciences, H.No.8-2-626/B,

Road. No. 11, Banjara Hills, Hyderabad 500034, A.P, India

e-mail: drsrivallient@yahoo.co.in which was progressively increasing in size. There was no history of pain, dysphagia, hoarseness of voice, dyspnoea, cough or fever. Clinical examination revealed an ill defined swelling of $5 \times 3 \mathrm{~cm}$ size, medial to anterior border of sternocleidomastoid muscle extending from angle of mandible to level of middle of thyroid cartilage on left side. It was cystic in consistency with restricted mobility and without any signs of inflammation.

CT scan of neck revealed a soft tissue mass lesion in the left anterior triangle of neck (Fig. 1). A provisional diagnosis of branchial cleft cyst was made and patient was taken up for surgical excision under general anesthesia using a transverse skin crease incision. An ovoid soft tissue mass extending over the left carotid sheath was separated by blunt dissection from the carotid vessels and internal jugular vein and was removed in toto.

The examination of gross specimen revealed a mass of $4 \times 3 \mathrm{~cm}$ multiloculated pinkish mass whose histopathological examination revealed a presence of cortical lymphoid tissue and Hassall's corpuscles in medulla (Fig. 2), characteristic of a thymic cyst and thus a diagnosis of cervical thymic cyst was made postoperatively. The postoperative period was uneventful and there is no recurrence even after 6 months of follow up.

\section{Discussion}

Embryologically, the thymus gland is derived from the ventral surface of third pharyngeal pouch in the sixth week of intrauterine life. Thymic buds of one side fuses with that of the opposite side and form a thymopharyngeal duct within which cellular proliferation takes place. Eventually superior part of thymopharyngeal duct gets regressed and failure to do so in its path may later lead on to formation of 


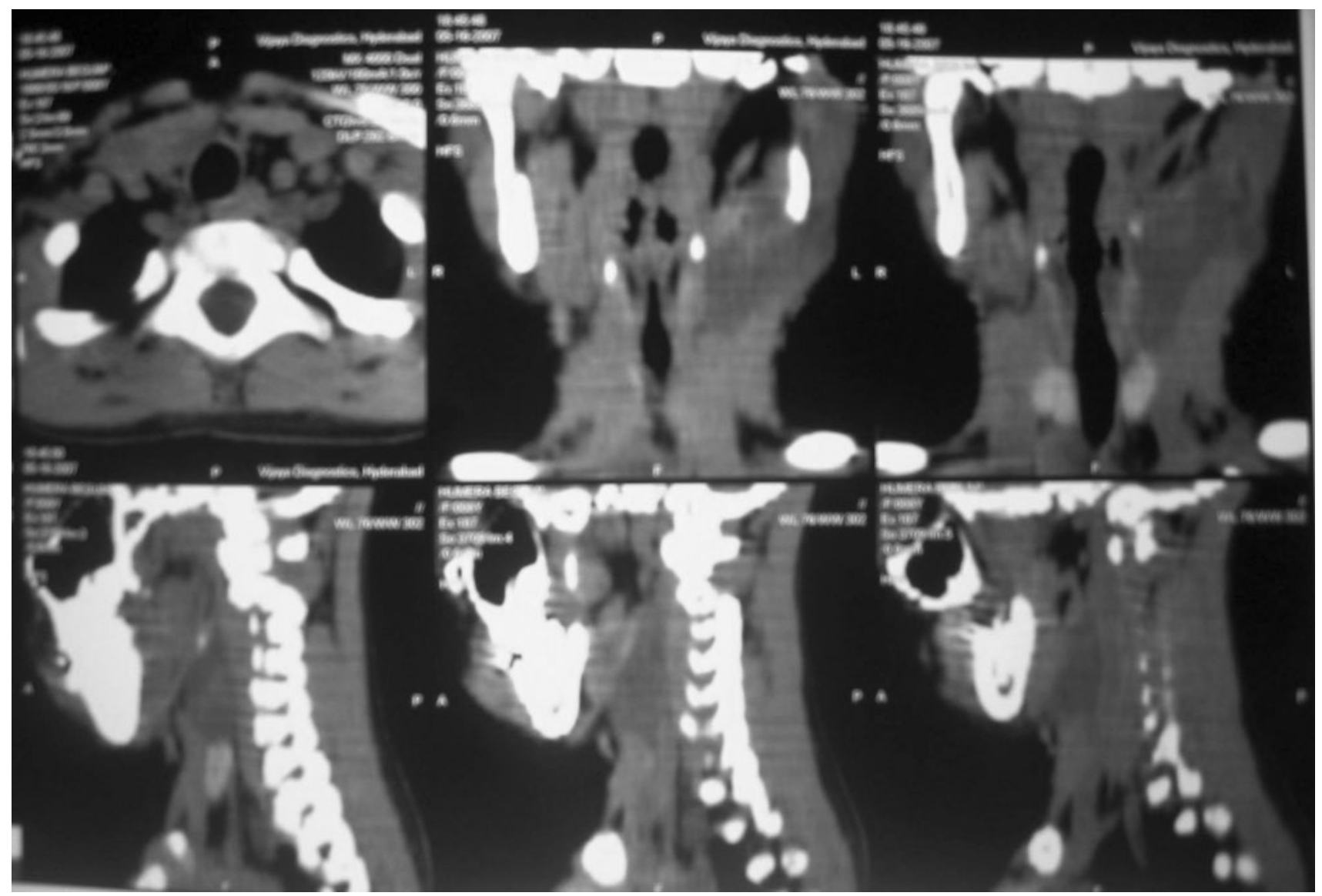

Fig. 1 CT scan of neck on sagittal and coronal reconstruction showing soft tissue lesion in upper part of left side of neck close to the carotid sheath

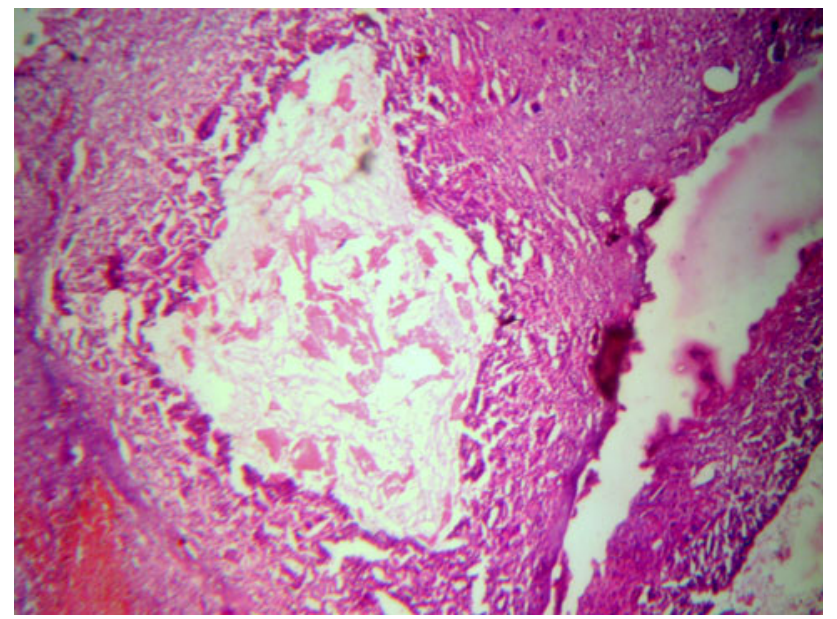

Fig. 2 Histopathological examination showing epithelial lined Hassall's corpuscle in loosely arranged medulla of thymic tissue with cystic spaces

thymic cyst. Two theories, firstly the persistence of thymopharyngeal duct and secondly the degeneration of Hassall's corpuscles, are considered plausible in regard to pathogenesis of thymic cyst by proposed by Speer [3-5].
Thymic cysts are more common in children in contrast to ectopic cervical thymus which is more common in adults. The occurrence of cervical thymic cysts is rare and diagnosis is difficult as most cases are asymptomatic. Majority of these cases are found anterior to sternocleidomastoid and are more common on right side. In 6-13\% cases [6] patient may present with stridor, hoarseness of voice or dysphagia. Computerized Tomography and Magnetic Resonance Imaging play an important role in detecting the lesion and its relationship to major vessels and mediastinal extension. Histopathologic examination is the only definitive means of diagnosis [2, 7, 8, 10]. Malignant degeneration is not reported in children probably due to absence of active solid thymic tissue but is a rare possibility in adults with ectopic cervical thymic mass [9]. Very rarely cyst may adhere to surrounding structures, like Internal Jugular Vein, Internal Carotid Artery, Vagus, Phrenic, Hypoglossal, or Recurrent Laryngeal nerves [2]. Differential diagnosis includes Branchial cleft cyst, cystic hygroma and thyroglossal duct cyst. The main modality of treatment is surgical excision after ruling out possibility of immunological disturbance. 


\section{Conclusion}

Cervical thymic cysts should be considered in differential diagnosis of cervical cystic masses presenting in children. Prior evaluation before cervical thymectomy should be done to confirm the presence of normal mediastinal thymus to prevent immune deficiency which may arise in very young children after cervical thymectomy if it is the only thymus tissue present.

Conflict of Interest None

\section{References}

1. Reiner M, Beck AR (1980) Cervical thymic cysts in children. Am J Surg 139(5):704-707
2. Nguyen Q, de Tar M, Wells W, Crockett D (1996) Cervical thymic cyst: case reports and review of the literature. Laryngoscope 106(3 Pt 1):247-252

3. Speer FD (1938) Thymic cysts. Bull N Y Med Col 1:142-150

4. Wagner CW, Vinocur CD, Weintraub WH, Golladay ES (1988) Respiratory complications in cervical thymic cysts. J Pediatr Surg 23(7):657-660

5. Miller MB, De Vito MA (1995) Cervical thymic cyst. Otolaryngol Head Neck Surg 112(4):586-588

6. Lyons TJ, Dickson JA, Variend S (1989) Cervical thymic cysts. J Pediatr Surg 24(3):241-243

7. Millman B, Pransky S, Castillo J III et al (1999) Cervical thymic anomalies. Int J Pediatr Otorhinolaryngol 47(1):29-39

8. Hendrickson M, Azarow K, Ein S et al (1998) Congenital thymic cysts in children-mostly misdiagnosed. J Pediatr Surg 33(6):821-825

9. Leong AS, Brown JH (1984) Malignant transformation in a thymic cyst. Am J Surg Pathol 8(6):471-475

10. Prasad KK, Gupta RK, Jain M et al (2001) Cervical thymic cyst: report of a case and review of the literature. Indian J Pathol Microbiol 44(4):483-485 